\title{
Low-Velocity Damage Zone on the San Andreas Fault at Depth near SAFOD Site at Parkfield Delineated by Fault- Zone Trapped Waves
}

\author{
by Yong-Gang Li, Peter E. Malin, and John E. Vidal
}

doi:10.2204/iodp.sd.s01.09.2007

\section{Introduction}

We deployed a dense linear array of forty-five seismometers across and along the San Andreas fault (SAF) near the SAFOD site at Parkfield in 2003 to record fault-zone trapped waves generated by near-surface explosions and microearthquakes located within the fault zone. Observations and 3-D finite-difference simulations of the fault-zone trapped waves generated by microearthquakes at different depths show a 100-200-m-wide low-velocity zone (LVZ) along the SAF reaching to depths of $6-7 \mathrm{~km}$ or more, within which shear velocities are reduced by $20 \%-40 \%$ on average from wall-rock velocities, with the maximum velocity reduction of $40 \%-50 \%$ in a $30-40$-m-wide fault core zone, indicating the localization of severe damage on the SAF. The damage zone is not symmetric but extends farther on the southwest side of the main fault trace. The width and velocities of this zone delineated by trapped waves are confirmed by the results of the SAFOD drilling and logs that show high porosity and multiple slip planes in a $\sim 200$-m-wide LVZ across the SAF with velocity reduction of $\sim 20 \%-30 \%$ at $\sim 3.2 \mathrm{~km}$ depth, within which a $\sim 35$-m-wide severely damaged zone is seen around the main slip (Hickman et al., 2005). Recently, the downhole seismograph installed in the SAFOD mainhole at $\sim 3 \mathrm{~km}$ depth recorded prominent fault-zone guided waves with long-duration dispersive wavetrains after $S$-arrivals from microearthquakes occurring below (Ellsworth and Malin, 2006). Finite-difference simulations of these waves show a $\sim 30-40$-m-wide core zone with velocities as low as $50 \%$ of the intact rocks embedded in the wider fault zone with intermediate velocity reduction, indicating that the damage zone on the SAF at Parkfield extends to the depth of at least several kilometers below $3 \mathrm{~km}$.

\section{The Fault Zone Observatory}

The spatial extent of fault weakness, and the loss and recouping of strength across the earthquake cycle are critical ingredients in our understanding of fault mechanics. In order to relate present day crustal stresses and fault motions to the geological structures formed in their past earthquake histories, such as the matured San Andreas Fault (SAF), we must understand the evolution of fault systems on many spatial and time scales. Extensive field and laboratory research and numerical simulations indicate that fault zones undergo high, fluctuating stress and pervasive cracking during an earthquake (Chester et al., 1993). While we know slip is localized on faults because of their lower strength compared to the surrounding bedrock, the magnitude of strength reduction and its spatial extent at seismogenic depth are still not well constrained (Hickman and Evans, 1992).

Near Parkfield, California, many researchers have observed a LVZ surrounding the surface trace the SAF (Roecker et al., 2004; Thurber et al., 2003; Unsworth et al., 1997). This zone is from a few hundred meters to $1 \mathrm{~km}$ wide, and has velocity reductions of $10 \%-30 \%$ and $V p / V s$ ratios on the order of 2.3. The LVZ is thought to be caused by intense fracturing during earthquakes, brecciation, liquid-saturation, and possibly high pore-fluid pressures near the fault core. Recent results from drilling logs at the Parkfield San Andreas Fault Observatory at Depth (SAFOD) show a LVZ more than one hundred meters wide at $\sim 3 \mathrm{~km}$ depth, indicating a severely damage zone associated with the SAF (Hickman et al., 2005). Pore fluids arising from depth appear to hold a complex relationship with this damage zone, with its outer portions appearing to be more permeable than its core (Lockner et al., 2000).

Highly damaged fault rocks along the SAF at Parkfield create a LVZ that can trap seismic waves (Ben-Zion, 1998; Li et al., 1990). Using fault-zone trapped waves generated by explosions and microearthquakes, and recorded at surface seismic arrays at Parkfield, Li et al. $(1997,2004)$ have delineated a $150-200$-m-wide low-velocity waveguide along the $\mathrm{SAF}$, appearing to extend to seismogenic depths beneath

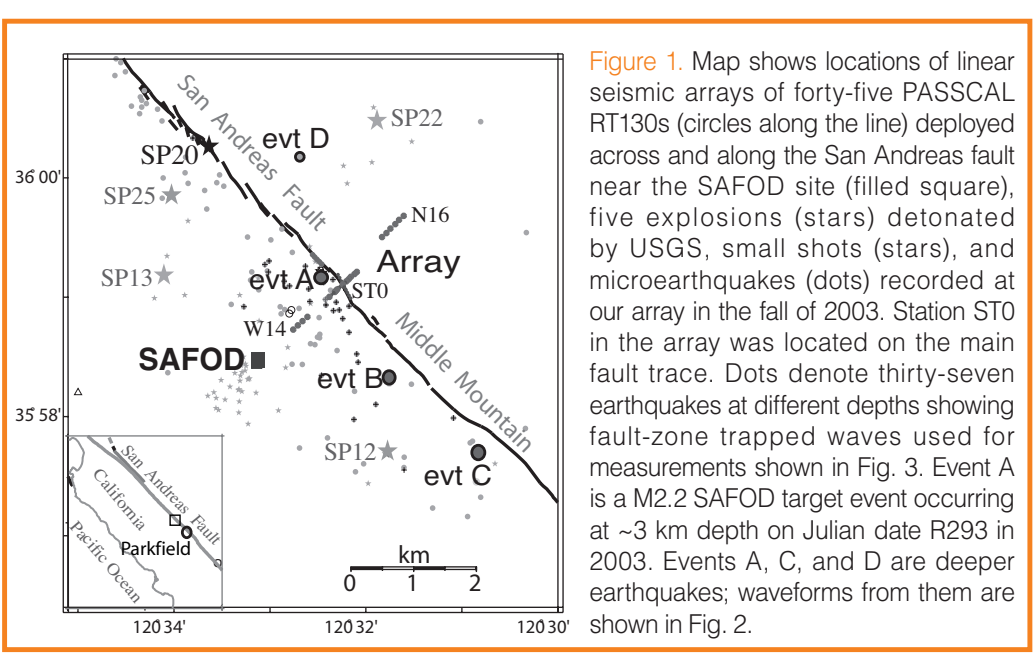


Middle Mountain, within which the shear-velocities are reduced by $20 \%-50 \%$. This distinct zone is interpreted as being a damage zone along the SAF that accumulated in the recurrence of ruptures in major earthquakes over geological time.

Recently, prominent fault-zone guided waves have been recorded in the SAFOD mainhole at $\sim 3 \mathrm{~km}$ depth, suggesting that a SAF-related low-velocity waveguide extends to deeper levels (Ellsworth and Malin, 2006). In this article, we discuss the fault-zone trapped waves recorded at the linear seismic array deployed across the SAF near the SAFOD site in 2003 and at the seismometers installed in the SAFOD mainhole. The data from local microearthquakes occurring at different depths provide better constraints on the depth extent of the damage structure of the SAF. These results help extend the direct measurements of fault-zone properties in the SAFOD mainhole to a 3-D structural image of the SAF zone.

\section{Data and Results}

Coordinated by SAFOD PIs, in the fall of 2003 we deployed a dense linear seismic array of forty-five PASSCAL RT130 seismometers across and along the SAF near the SAFOD

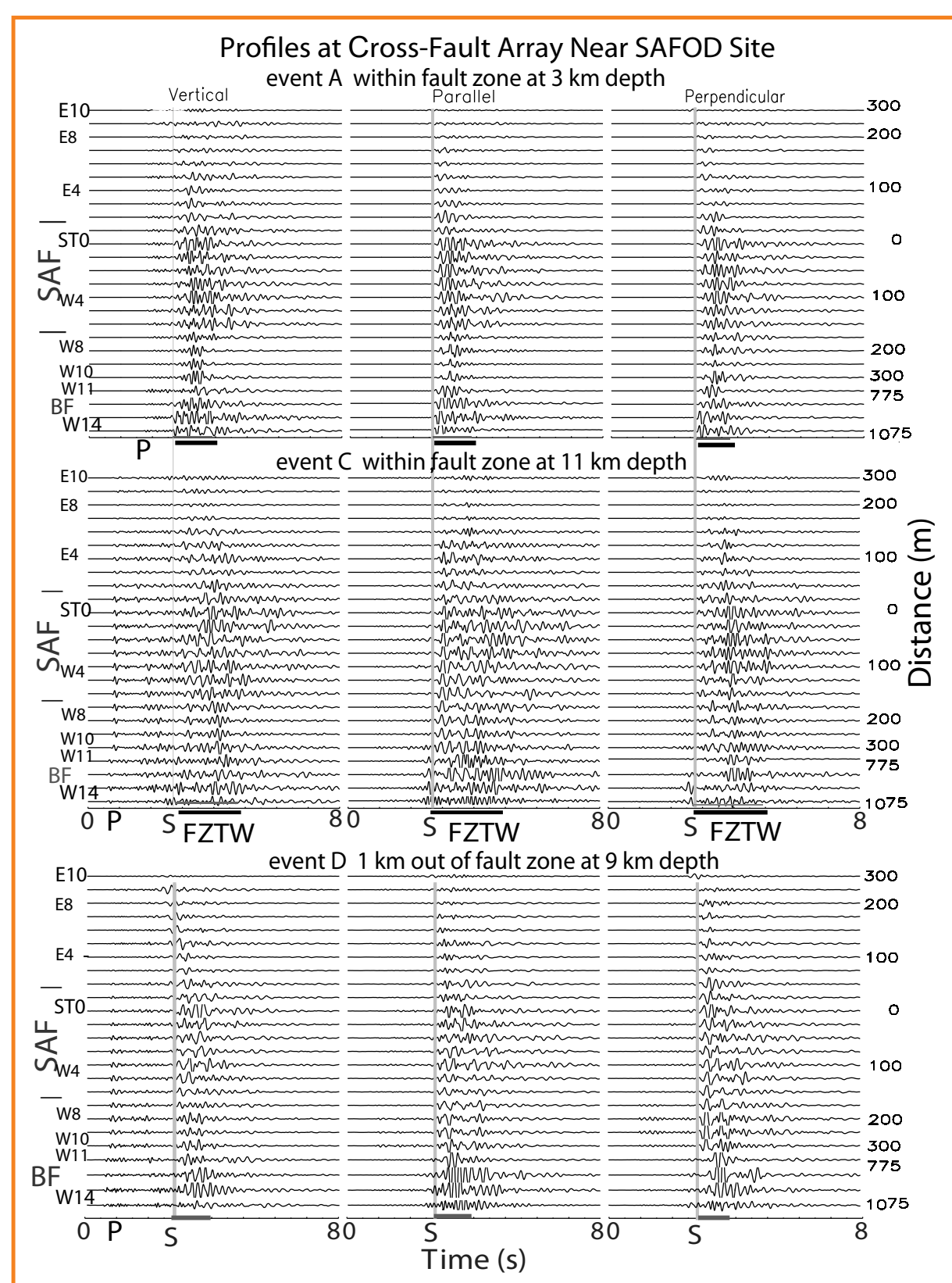

Figure 2. Three-component seismograms at the cross-fault array for three microearthquakes occurring near the SAFOD site. Seismograms have been $<6-\mathrm{Hz}$ filtered and plotted in a fixed amplitude scale in each plot. Prominent fault-zone trapped waves (FZTWs) with large amplitudes and long wavetrains after S-arrivals from the on-fault events $A$ and $C$ arrive at stations between E6 and W4 in a $\sim 200-m$ range across the SAF. Vertical lines are aligned with S arrivals. Horizontal bars denote wavetrain lengths of FZTWs after S-arrivals. The FZTW wavetrains from event $C$ occurring at $\sim 11 \mathrm{~km}$ is $\sim 2.2 \mathrm{~s}$ long, but is $\sim 1.2 \mathrm{~s}$ for event $A$ at $\sim 3 \mathrm{~km}$. The wavetrain for the off-fault event $\mathrm{D}$ occurring at the similar depth of event $\mathrm{C}$ is much shorter, indicating that the low-velocity waveguide on the SAF likely extends down to the depth at least $3 \mathrm{~km}$. Some seismic energy is trapped within the branch fault (BF) site $\sim 15 \mathrm{~km} \mathrm{NW}$ of Parkfield to record fault-zone trapped (guided) waves for site characterization before drilling (Fig. 1). We recorded 100 local earthquakes occurring at depths between $2 \mathrm{~km}$ and $12 \mathrm{~km}$ and five explosions in the fan-geometry detonated by the USGS researchers. The fault-zone trapped waves (FZTWs) generated by microearthquakes and explosions are used to delineate the rock damage extent and physical properties along the SAF at seismogenic depths.

Figure 2 exhibits seismograms recorded at cross-fault array for three microearthquakes near the SAFOD site, showing prominent FZTWs with large amplitudes and long wavetrains after $S$-arrivals at stations close to the SAF main trace in a width range of 150-200 $\mathrm{m}$ for events A and C occurring within the fault zone. In contrast, trapped waves are not clear at the same stations for event D occurring $\sim 1 \mathrm{~km}$ away from the fault zone, and stations located out of the fault zone register brief body waves for these three events, indicating the existence of a LVZ to form a waveguide along the SAF. It is seen that the LVZ extends farther on the southwest side of the main fault trace on which station ST0 was located. We noted some seismic energy trapped within a branch fault (BF) which may connect to the main fault at depth. The FZTWs partitioned from the main fault to this branch fault have been recorded at the borehole seismograph installed in the SAFOD mainhole (Malin et al., 2006). The FZTWs from event $\mathrm{C}$ occurring at $\sim 11 \mathrm{~km}$ depth show much longer wavetrains than those from the shallower event $\mathrm{A}$ at the $3 \mathrm{~km}$ depth, 
indicating that the low-velocity waveguide on the SAF likely extends to seismogenic depths deeper than $3 \mathrm{~km}$. In contrast, the same stations registered much shorter wavetrains after $S$-arrivals for the off-fault event D at $\sim 9 \mathrm{~km}$ depth compared to those from the on-fault event $\mathrm{C}$, although these two events occurred at a similar depth and distance from the array. In order to examine the depth extension of the LVZ on the SAF, we used the data from thirty-seven local earthquakes located within the fault zone at different depths with the raypath incidence angles to the array smaller than $30^{\circ}$ from vertical (Fig. 3A). Figure 3B shows seismograms and envelopes at station ST0 located on the main fault trace for eleven on-fault events at different depths near the SAFOD site. $S$-arrivals for these events are aligned at $2 \mathrm{~s}$. The length of fault-zone trapped wavetrains following $S$-arrivals progressively increases from $\sim 1.2 \mathrm{~s}$ to $\sim 2.2 \mathrm{~s}$ as the event depths increase from $2.6 \mathrm{~km}$ to $11.7 \mathrm{~km}$. In contrast, much shorter wavetrains after $S$-arrivals with flat changes in length are registered at the same station for eleven other events located away from the fault zone in a similar depth range. Figure $3 \mathrm{C}$ shows the measured wavetrain lengths of FZTWs registered at stations within the fault zone for thirty-seven on-fault events and thirteen off-fault events at depths between $2 \mathrm{~km}$ and $12 \mathrm{~km}$. The lengths of FZTWs for on-fault events increase from $1.0 \mathrm{~s}$ to $2.2 \mathrm{~s}$ as the depth increases from $\sim 2 \mathrm{~km}$ to $\sim 12 \mathrm{~km}$, but shorter wavetrains with flat depth-dependent changes are measured at the same stations for off-fault events. Stations located out of the fault zone registered much short wavetrains after $S$-arrivals for all these events. These observations indicate that the low-velocity waveguide formed by the damage zone on the SAF extends across seismogenic depths to at least $\sim 7 \mathrm{~km}$, although the velocity reduction (damage magnitude) within the zone becomes smaller with depth due to the larger confined stress at greater depths.

In the fall of 2005, a borehole seismograph was placed down the SAFOD mainhole at a depth of $\sim 3 \mathrm{~km}$, where the SAFOD drilling and logging records suggest the active SAF is present (Hickman et al., 2005). This downhole seismograph recorded prominent fault-zone guided waves from the deeper events (Ellsworth and Malin, 2006). For example, Figure 4 shows FZTWs with large amplitudes and long dispersive wavetrains generated by an aftershock of the M6 Parkfield earthquake at $\sim 6 \mathrm{~km}$ depth within the fault zone, indicating the existence of a continuous low-velocity fault core zone between this event and the borehole seismometer. Thus, the damage zone on the SAF must extend at least several kilometers below the $3 \mathrm{~km}$ depth.

Based on our observations of fault-zone trapped waves at the surface array and borehole seismometer in the SAFOD mainhole, we constructed a velocity and $Q$ model across the SAF near the SAFOD site (Fig. 5A). The wall-rock velocities are constrained by tomography profiles at Parkfield (Roecker et al., 2004; Thurber et al., 2003). Using a 3-D FD code (Graves, 1996), we simulated FZTWs generated by explosions to determine the shallow $1-2 \mathrm{~km}$ fault zone structure,

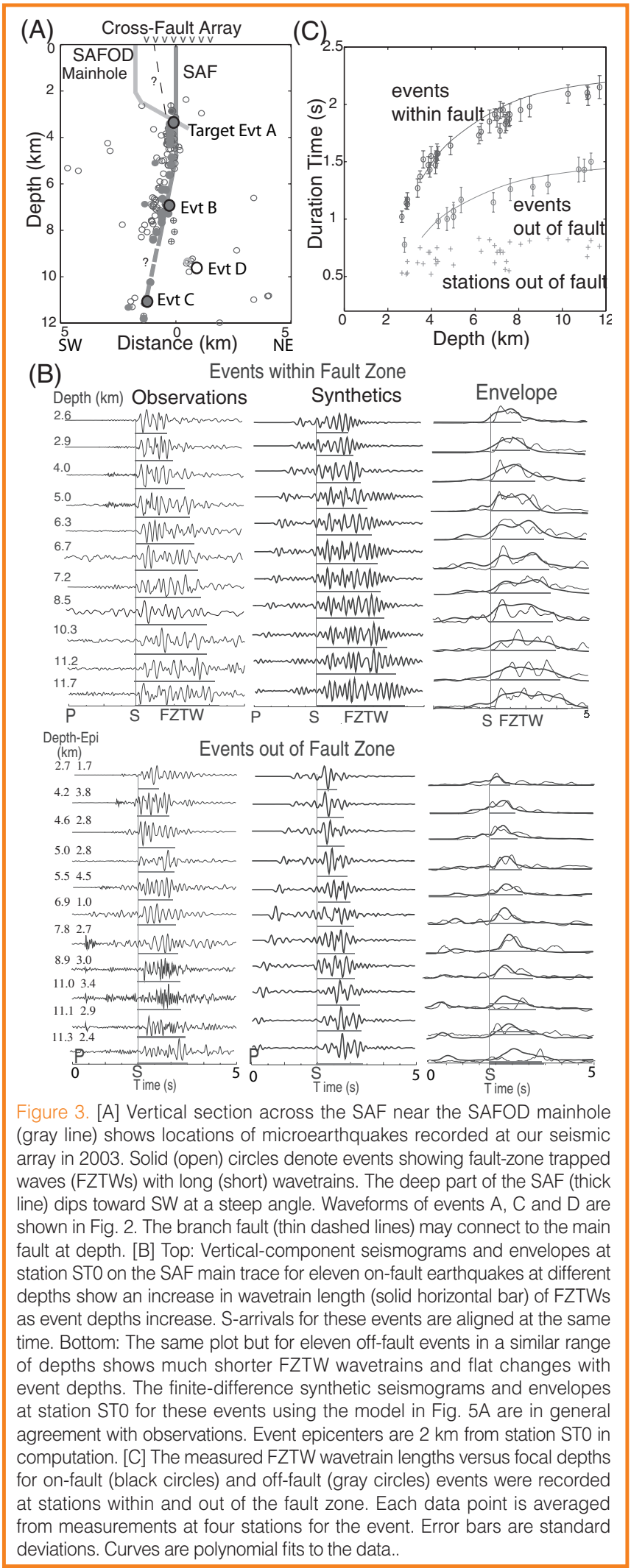

and then simulated trapped waves from earthquakes at different depths and epicentral distances to obtain a model of the SAF with depth-variable structure at seismogenic depths. The width and velocities of the damage zone at $3 \mathrm{~km}$ depth in this model are constrained by the logging measurements in the SAFOD mainhole (Fig. 5B) (Hickman et al., 2005). For examples, Fig. 4B shows 3-D finite-difference synthetic 
seismograms for the SAFOD drilling target event occurring $\sim 3 \mathrm{~km}$ near the array site using the model in Fig. 5A. Figure $4 \mathrm{C}$ exhibits synthetic seismograms at the SAFOD mainhole seismograph located at $3 \mathrm{~km}$ depth within the fault core zone for a deep event at $6 \mathrm{~km}$ with the epicenter $3 \mathrm{~km} \mathrm{SW}$ of the site using the same model. We obtained a good fit of synthetics to observations, suggesting that this model is applicable for
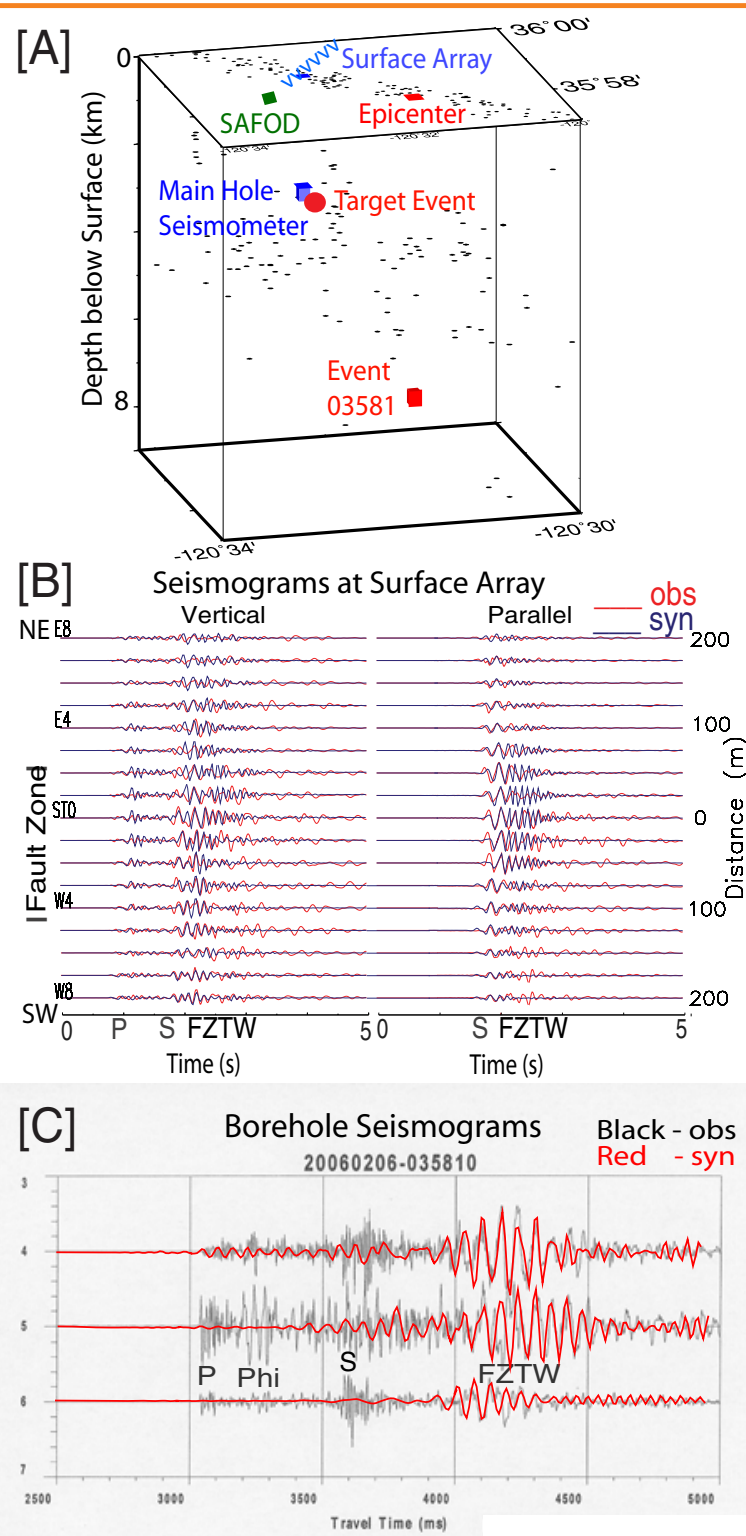

Figure 4. [A] 3-D view of locations of aftershocks (black dots) of the 2004 M6 Parkfield earthquake recorded at the SAFOD mainhole seismograph (blue square). The red square denotes an example event (03581) occurring at $\sim 6 \mathrm{~km}$ depth within the fault zone with its epicenter $\sim 3 \mathrm{~km}$ SE of the surface array (blue Vs) shows prominent FZTWs at the borehole seismograph (see Fig. 4C). The red dot denotes the SAFOD drilling target event. [B] Observed and 3-D finite-difference synthetic seismograms at the surface array across the SAF for the SAFOD drilling target event at $\sim 3 \mathrm{~km}$ depth using the velocity model in Fig. 5A. A double-couple source is located within the fault core zone. Seismograms have been $<8-\mathrm{Hz}$ filtered and are plotted using a fixed amplitude scale for all traces. [C] Three-component seismograms recorded at the seismometer with the $15-\mathrm{Hz}$ sensor in the SAFOD mainhole at $\sim 3 \mathrm{~km}$ for a Parkfield aftershock at $\sim 6 \mathrm{~km}$ (see Fig. 4A) contain direct P- and S-waves followed by lower frequency FZTWs after $\sim 0.5 \mathrm{~s}$ and again after $\sim 1 \mathrm{~s}$. The large dispersed phase between the $\mathrm{P}$ and $\mathrm{S}$ waves is labeled by "Phi", referring to its likely origin in the general leaky mode type wave motion associated with special low velocity waveguides (Ellsworth and Malin, 2006). 3-D finite-difference synthetic seismograms using the velocity model in Fig. 5A match the FZTWs recorded at the borehole seismometer. interpretation of the damage structure on the SAF at Parkfield to at least $6 \mathrm{~km}$. Using the fault-zone model in Fig. 5A, we also simulated seismograms at station ST0 on the main fault trace for eleven on-fault earthquakes and eleven off-fault earthquakes at depths between $3.6 \mathrm{~km}$ and $11.2 \mathrm{~km}$ for comparison with observed seismograms at this station (Fig. 3). The lengths of synthetic FZTW wavetrains increase with the event depth for on-fault events, which generally agrees with observations. On the other hand, the synthetic seismograms for off-fault events showed much shorter wavetrains after $S$-arrivals and less change in the wavetrain length with depth. These modeling results further indicate that the low-velocity waveguide (damage zone) on the SAF at Parkfield likely extends across the seismogenic depth of at least $6-7 \mathrm{~km}$.

\section{Conclusion}

Observations and modeling of fault-zone trapped waves recorded at dense linear seismic arrays across the SAF at the surface and at the downhole seismograph installed in the SAFOD mainhole show the existence of a distinct lowvelocity damage zone along the SAF at Parkfield, within which seismic velocities are reduced by $30 \%-50 \%$ from wallrock velocities. The damage zone likely extends to the depth of at least $6-7 \mathrm{~km}$. This zone is thought to be caused by intense fracturing during earthquakes, brecciation, liquidsaturation, and possibly high pore-fluid pressure nears the fault. The damage zone is asymmetric, broader on the southwest side of the main fault trace. The asymmetry may imply that the fault zone has a significant cumulative damage due to previous large earthquakes on the SAF. When a fault ruptures, it may preferentially damage the already weakened rocks in the zone, even though those rocks are not symmetrically distributed on either side of the main slip plane (Chester et al., 1993). Alternately, greater damage may be inflicted in the extensional quadrant than the compressional quadrant near the propagating crack tip (Andrews, 2005).

Although the structural model for the SAF at Parkfield delineated by FZTWs (Fig. 5A) explains part of the data, it is still a simple one. The true structure in three dimensions may be more complicated. It will be further studied using more data from deep events recorded at surface and downhole seismic arrays to document variations in the extent and magnitude of rock damage along the fault strike and with depth, as well as their relationship with the rupture distribution and stress variations over multiple length and time scales. This study contributes essential information towards further understanding of faulting mechanics and earthquake hazards at matured faults like the San Andreas fault.

\section{Acknowledgments}

This study is supported by EarthScope GrantEAR0342277, USGS Grant NEHRP20060160, and the SCEC. Special thanks to S. Hickman, W. Ellsworth, and M. Zoback for their 


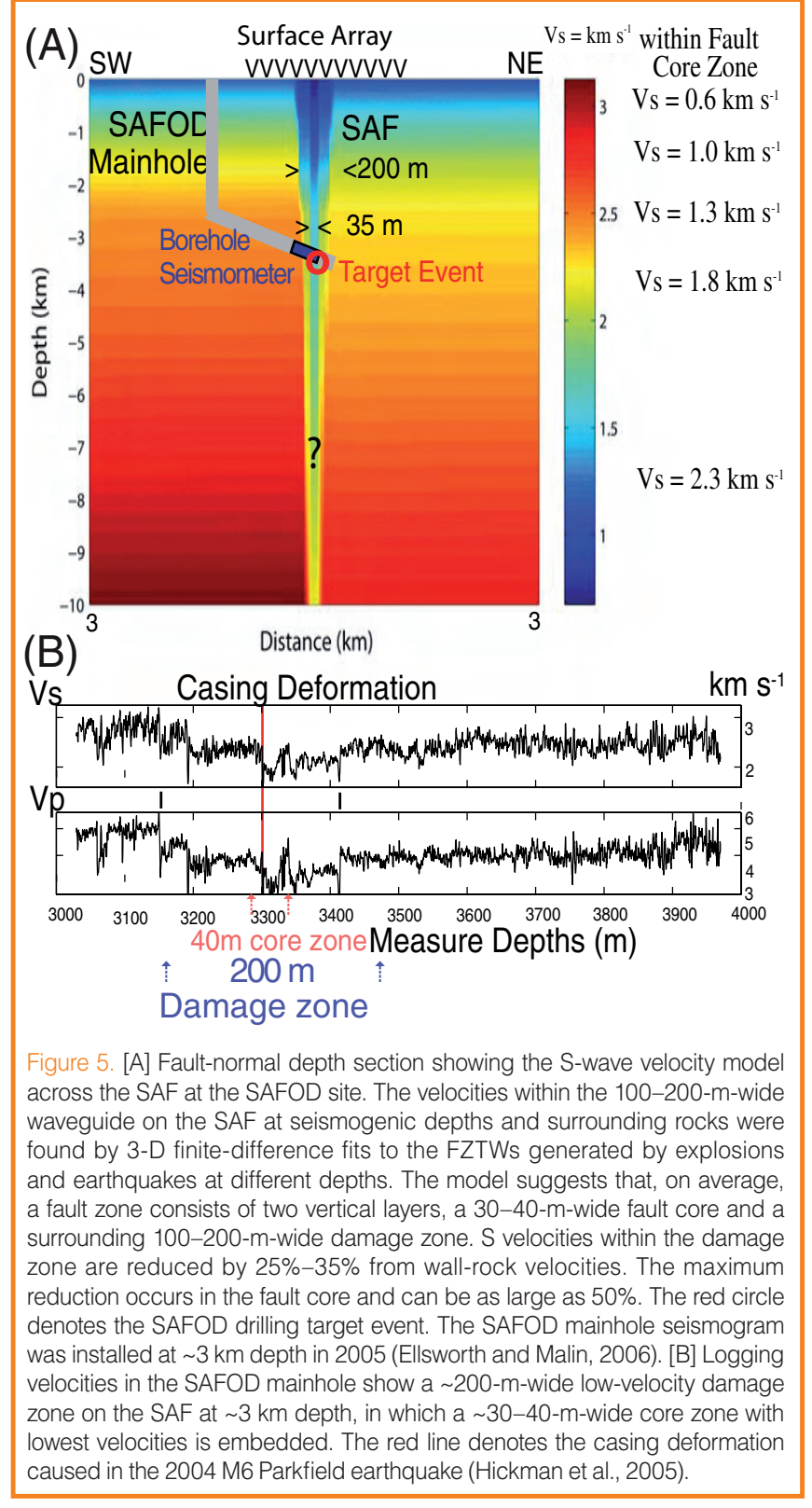

coordination, and E. Cochran, C. Thurber, S. Roecker, M. Rymer, R. Catchings, A. Snyder, L. Powell, B. Nadeau, N. Boness, and D. McPhee for their collaborations in our experiments at Parkfield. The author was supported by the ICDP to attend the ICDP-IODP Fault-Zone Drilling Workshop in Japan in 2006.

\section{References}

Andrews, D.J., 2005. Rupture dynamics with energy loss outside the slip zone. J. Geophys. Res., 110:B01307, doi:0.1029.

Ben-Zion, Y., 1998. Properties of seismic fault zone waves and their utility for imaging low-velocity structure. J. Geophys. Res., 103:12567-12585.

Chester, F., Evans, J., and Biegel, R., 1993. Internal structure and weakening mechanisms of the San Andreas fault.J. Geophys. Res., 98:771-786.

Ellsworth, W.L. and Malin, P.E., 2006. A first observation of fault guided PSV-waves at SAFOD and its implications for fault characteristics. EOS, Trans. AGU, 87(52), Abstract T23E-02.
Hickman, S.H. and Evans, B., 1992. Growth of grain contacts in halite by solution-transfer: Implications for diagenesis, lithification, and strength recovery. In Evans, B., and Wong, T.-F. (Eds.), Fault Mechanics and Transport Properties of Rocks, San Diego, Calif., (Academic Press), 253-280.

Hickman, S.H., Zoback, M.D., and Ellsworth, W.L., 2005. Structure and composition of the San Andreas fault zone at Parkfield: Initial results from SAFOD Phase 1 and 2. EOS, Trans. AGU, 83(47):237.

Li, Y.G., Ellsworth, W., Thurber, C., Malin, P., and Aki, K., 1997. Observations of fault-zone trapped waves excited by explosions at the San Andreas fault California. Bull. Seism. Soc. Am. 87:210-221.

Li, Y.G., Leary, P., Aki, K., and Malin, P., 1990. Seismic trapped modes in Oroville and San Andreas fault zones. Science, 249:763766.

Li, Y.G., Vidale, J.E., and Cochran, S.E., 2004. Low-velocity damaged structure on the San Andreas fault at Parkfield from faultzone trapped waves. Geophys. Res. Lett. 31:L12S06.

Lockner, D., Naka, H., Tanaka, H., Ito, H., and Ikeda, R., 2000. Permeability and strength of core samples from the Nojima fault of the 1995 Kobe earthquake. USGS Open file, Report 00-129, 147-152.

Malin, P.M., Shalev, E., Balven, H., and Lewis-Kenedi, C., 2006. Structure of the San Andreas Fault at SAFOD from P-wave tomography and fault-guided wave mapping. Geophys. Res. Lett., 33:L13314, doi: 10.1029/2006GL025973.

Roecker, S., Thurber, C., and D. McPhee. 2004. Joint inversion of gravity and arrival time data from Parkfield: New constraints on structure and hypocenter locations near the SAFOD drill site. Geophys. Res. Lett., 31:L12S04, doi: 10.1029/2003GL019396.

Thurber, C., Roecker, S., Roberts, K., Gold, M., Powell, L., and Rittger, K., 2003. Earthquake location and 3-D fault zone structure along the creeping section of the San Andreas fault near Parkfield, CA: Preparing for SAFOD. Geophys. Res. Lett. 30:1112-1115.

Unsworth, M., Malin, P., Egbert, G., and Booker, J., 1997. Internal structure of San Andreas fault at Parkfield, CA. Geology, 356-362.

\section{Authors}

Yong-Gang Li, Zumberge Hall, Department of Earth Sciences, University of Southern California, 3651 Trousdale Parkway, Los Angeles, Calif. 90089, U.S.A., e-mail: ygli@ usc.edu.

Peter E. Malin, Division of Earth and Ocean Sciences, 109A Old Chemistry Box 90227, Duke University, Durham, N.C., 27708, U.S.A.

John E. Vidale, Department of Earth and Space Sciences, University of California, 595 Charles Young Drive East, Box 951567, Los Angeles, Calif., 90095-1567, U.S.A. 